\title{
'Confidential Inquiry into Homicides and Suicides by Mentally III People. A Preliminary Report on Homicide'
}

\author{
Paul Bowden
}

Although this report is preliminary, it is not difficult to sense the way the inquity is going: along the route mapped out by the care programme approach (CPA). That is not surprising given the membership of the inquiry team, a rag-bag of administrators, two professors of general psychlatry and a forensic psychiatrist. (Where are the criminologists, psychologists, sociologists, and academic forensic psychiatrists who have done all this before?). Judging by the urgency with which the supervision register has been promoted and the passive line which the College has taken in response, it is reassuring that obeyance isn't given by the injury to it as yet another panacea.

The inquiry focuses on 22 cases of homicide, which is an offence category of unlawful kdling. where the perpetrator was mentally disordered. Behaviour which does not result in kdlling or which is not criminalised is ignored. As the incidence of violent crime, including homicide, rises inexorably the proportion which is a direct result of mental iliness falls. The per capita rate of offending by mentally ill people is probably relatively stable, reflecting as it does the prevalence of mental illness in the general population whereas the other causes of violence are having a field-day. Why then focus on the mentally III? Is not society well enough protected from their depredations?

The media, grown fat from their exploitation of successtve waves of moral panic which they have themselves engineered, portray each kdlling by a mentally ill person as a fallure of community care.

Those who see themselves as responsible for community care divest themselves of their guilt by targeting others with approbation. settling on the smallest and the weakest. By the time the supervision reglster hits the streets it will be the key-worker, standing disconsolately on the step in front of a firmly closed door, who carries the can.

Seemingly oblivious of the vast research evidence on the nature of the relationship between mental illness and violent offending and driven by political correctness, the inquiry focuses on the finding that $60 \%$ of the mentally ill killers had recently fallen out of treatment. In the audacious words of the report: "In most cases it had not been thought necessary to increase supervision or to take spectal precautions prior to the offence". Of course the inference is that some kdlilings could have been predicted and it only takes a nudge and a wink to lead us to the corollary: increased supervision might have prevented the kdling. Bring on the CPA and the supervision register. or beware of false gods?.

Putting aside serious violence that is wholly unpredictable, it may be the case that in many killers substance abuse coexists with mental illness. Or it may be that it is certain aspects of personality which have the greatest influence in determining violence. How are the different contributions of the two addressed by the care programme approach? Is it not that the determinants of a single act of violence are so complex that to single out one is to be guilty of an act of supreme natvety? And what if our confidence in neuroleptics as controllers of human behaviour is fatally flawed?.

For certain offenders who are thought to present a risk we have restriction orders (sections 37-41, Mental Health Act 1983) which provide punittve distncentives to non compliance. Risk to others is also a criterion for the ctvil sections of the 1983 Act. For other 
objecting and objectionable patients Special Weapons and Tactics (SWAT) teams in the community are neutered by Parliament's fallure to provide bullets for their guns and the few secure beds which exist outside the special hospitals are always full. The prisons continue to provide respite secure care for the remainder of the NHS although their work is hindered by a complete lack of workable criteria by which those who are unable to, or refuse consent can be treated.

More secure beds are a prerequisite of regaining some control of the situation but recognising this need and doing something about it is an anathema to those who have been empowered by the flight into the community. Even an Ideal programme of community supervision could not predict that which cannot be predicted and it could not interfere with those vagaries of the human condition which sometimes have tragic consequences. We could target those with particular genetic loadings, or those with specific psychopathology, or those with particular attitudes to others but I suspect that when our successors look back at whatever interventions the era of community care brought they will notice hardly a blip on the screen.

Somewhere Professor Nigel Walker warned that simplistic explanations raise more questions than they answer. To say that a man killed his mother because he believed that he was John the Baptist tells us very little, the explanation raises questions and answers none. But perhaps that was the inquiry's purpose?

Paul Bowden, Consultant Forensic Psychiatrist, The Maudsley Hospttal, Denmark Hill, London SE5 8AZ

\title{
Psychopathic and Antisocial Personality Disorders
}

\author{
By Bridget Dolan \& Jeremy Coid
}

The effectiveness of treatment of people with psychopathic or antisocial personality disorders is a cause for concern among many health professionals. These patients manifest severe psychological disturbance, and their behaviour can be disruptive or even dangerous. This timely book provides an overview of contemporary diagnostic concepts of psychopathic disorder, a review of natural history studies, and a comprehensive assessment of outcome studies of various treatments considered in a range of settings (the community, non-secure hospitals, secure units, Special Hospitals, and prisons).

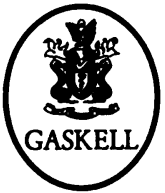

\section{$\bullet £ 20.00 \bullet 323 p p . \bullet 1993 \bullet$ ISBN 0902241664}

Available from the Publications Department, Royal College of Psychiatrists,17 Belgrave Square, London SW1X 8PG (Tel. 0171-235 2351) 